\title{
A REVIEW ON FIBER REINFORCED COMPOSITES
}

\author{
Malthumkar Mahesh ${ }^{1}$ and S. Venkat Prasat ${ }^{2}$ \\ ${ }^{1,2}$ Department of Mechanical Engineering, Nalla Malla Reddy Engineering College, \\ Hyderabad, Telangana, India
}

\begin{abstract}
Composites reinforced with fibers of synthetic or natural materials are gaining significant importance as requirements for lightweight materials along with high strength for specific applications are growing in the market. Fiber reinforced polymer composites (FRPCs) offer not only high strength to weight ratio, but also exhibit excellent properties such as high durability, stiffness, damping and flexural strength. FRPCs also possess high resistance to corrosion, wear, impact and fire. These wide range of diverse features have led FRPCs to find numerous applications in mechanical, construction, aerospace, automobile, marine and many other manufacturing sectors. A review of a diverse range of fibers, their properties, functionality, classification and various FRPC processing techniques are presented in this paper for selecting the suitable FRPCs for different applications. The exceptional performance of FRPCs in the various fields of applications has made them a promising alternative over monolithic metals or alloys.
\end{abstract}

Keywords: Fiber reinforced polymer composites, Carbon nanotubes, Resin transfer molding process, Electrospinning process.

Corresponding Author: S. Venkat Prasat

\section{INTRODUCTION}

Fiber-reinforced composites (FRCs) are composed of axial particulates embedded in a matrix material. The objective of fiber-reinforced composites is to obtain a material with high specific strength and high specific modulus. The strength is obtained by transmitting the applied load from the matrix to the fibers. Hence, interfacial bonding is very important in the case of FRCs. Classic examples of FRCs include fiberglass and wood. FRC is a composite building material that consists of three components:

1. Fibers as the discontinuous or dispersed phase

2. Matrix as the continuous phase

3. Fine interphase region, also known as the interface.

Rice husk, rice hull and plastic are utilized as ingredients. This technology involves refining, blending and compounding natural fibers from cellulosic waste streams to form a highstrength FRC material in a polymer matrix. The designated waste or base raw materials used in this instance are those of waste thermoplastics and various categories of cellulosic waste including rice husk and saw dust.

FRC is high-performance fiber composite achieved and made possible by cross-linking cellulosic fiber molecules with resins in the FRC material matrix through a proprietary molecular re-engineering process, yielding a product of exceptional structural properties. Through this feat of molecular re-engineering, selected physical and structural properties of wood are successfully cloned and vested in the FRC product, in addition to other critical attributes in order to yield performance properties superior to contemporary wood. This material, unlike other composites, can be recycled up to 20 times, allowing scrap FRC to be 
reused again and again. The failure mechanisms in FRC materials include delamination, intra laminar matrix cracking, longitudinal matrix splitting, fiber/matrix debonding, fiber pull-out and fiber fracture.

\section{CLASSIFICATION OF COMPOSITES}

Composite materials are classified according to their content, i.e., base material and filler material. The base material, which binds or holds the filler material in structures, is termed as a matrix or a binder material, while filler material is present in the form of sheets, fragments, particles, fibers, or whiskers of natural or synthetic material. As represented in Figure 1, composites are classified into three main categories based on their structure and fibers.

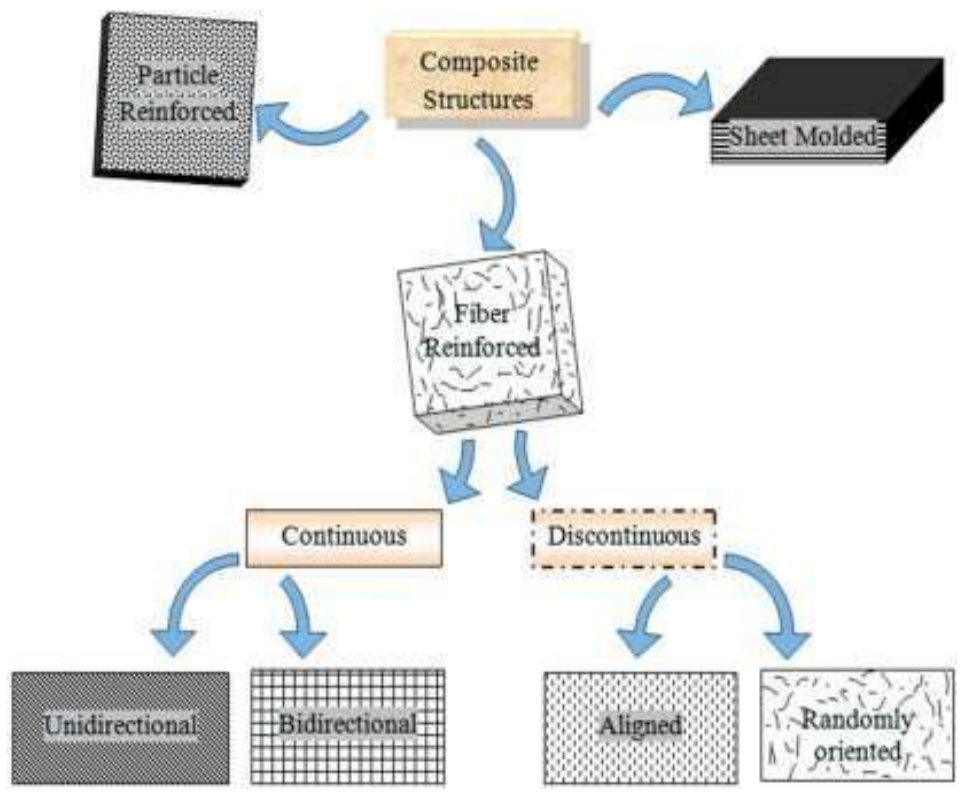

Figure 1: Classification of composites.

Composites consist of fibers in the matrix structure and can be classified according to fiber length. Composites with long fiber reinforcements are termed as continuous fiber reinforcement composites, while composites with short fiber reinforcements are termed as discontinuous fiber reinforcement composites. Hybrid fiber-reinforced composites are those where two or more types of fibers are reinforced in a single matrix structure. Fibers can be placed unidirectionally or bidirectionally in the matrix structure of continuous fiber composites, and they take loads from the matrix to the fiber in a very easy and effective way. Discontinuous fibers must have sufficient length for effective load transfer and to restrain the growth of cracks from avoiding material failure in the case of brittle matrices. The arrangement and orientation of fibers define the properties and structural behavior of composite material. Improvement in properties such as impact toughness and fatigue strength can be seen with the use of chemically treated natural fibers. Fibers of glass, carbon, basalt, and aramid in the dispersed phase were conventionally used in the matrix structure of fiberreinforced polymer (FRP) composite materials. FRPs can be further classified as natural fiber, synthetic fiber, hybrid fiber and particle reinforced composites.

\subsection{Natural Fiber Reinforced Composites}

Significant properties of natural fiber polymer composites (NFPCs) have potential applications in the modern industry, as researchers currently are compelled towards the development of environmentally friendly materials due to stringent environmental laws. 
There are numerous fibers available for composite materials and they are primarily categorized as natural or synthetic fibers. Further, recent studies have revealed unprecedented material properties when these two fibers are combined together, blending with a matrix material to form a hybrid composite. Natural fibers (NFs) are a very easy to obtain, extensively available material in nature. They reveal some outstanding material properties like biodegradability, low cost per unit volume, high strength, and specific stiffness. Composites made of NF reinforcements seem to carry some diverse properties over synthetic fibers, such as reduced weight, cost, toxicity, environmental pollution, and recyclability. These economic and environmental benefits of NF composites make them predominant over synthetic fiberreinforced composites for modern applications. Depending on the type, natural fibers have similar structures with different compositions. The inclusion of long and short natural fibers in thermoset matrices has manifested high-performance application. Some of the natural and synthetic fibers are shown in Figure 2.
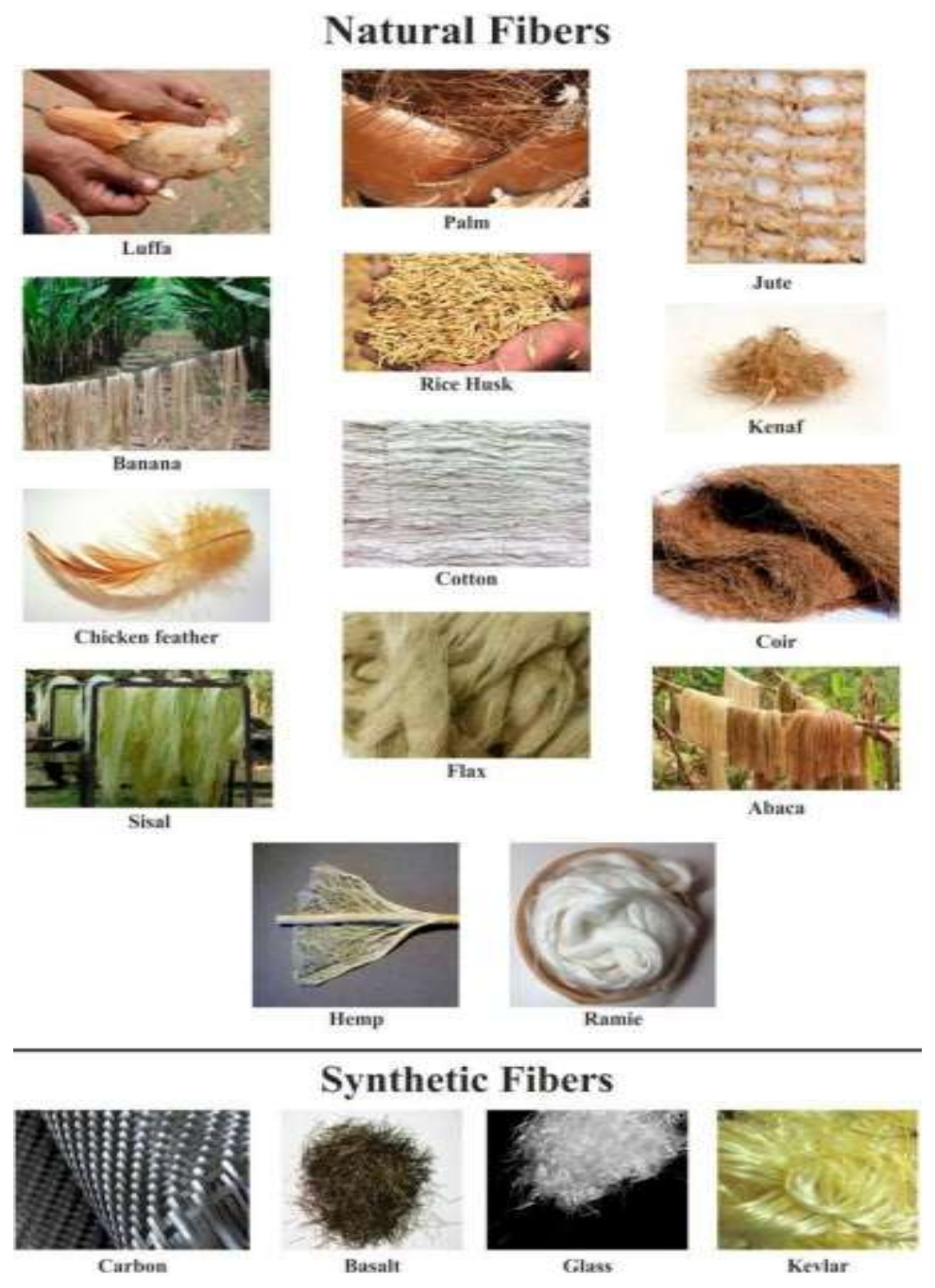

Figure 2: Types of fibers

\subsection{Synthetic Fiber Reinforced Composites}

Human-made fibers that are produced by chemical synthesis are called synthetic fibers and further classified as organic or inorganic based on their content. Generally, the strength and stiffness of fiber materials are much higher than that of the matrix material, making them a load-bearing element in the composite structure. Glass fibers (GFs) are most widely used 
among all the synthetic fibers as they offer excellent strength and durability, thermal stability, resistance to impact, chemical, friction, and wear properties. However, the machining of glass fiber-reinforced polymers (GFRPs) is relatively slow, challenging, and shows reduced tool life while working on conventional machining systems. GFs also carry the disadvantage of disposal at the end of their service life. However in some applications, more stiffness is required, so carbon fibers (CFs) are employed instead of GFs.

Graphene fibers are a new type of high-performance carbonaceous fibers that reflect high tensile strength with enhanced electrical conductivity when compared to carbon fibers. Several enhanced properties of graphene fibers show their potentiality in a variety of applications, such as lightweight conductive cables and wires, knittable super capacitors, micromotors, solar cell textiles, actuators, etc. Basalt fiber (BF) possesses better physical and mechanical properties over fiberglass. In addition, BF is significantly cheaper than carbon fibers. The effect of temperature on basalt fiber-reinforced polymer (BFRP) composites has been investigated, where there was an increase in static strength and fatigue life at a certain maximum stress observed with a decrease in temperatures.

Thermal properties of Kevlar fiber-reinforced composites (KFRCs) are enhanced by hybridizing it with glass or carbon fibers, though there is less research on the hybridization of Kevlar fibers (KFs) with natural fibers. KFRCs show high impact strength with a high degree of tensile properties, but due to their anisotropic nature they possess low compression strength compared to their glass and carbon fiber counterparts.

\subsection{Hybrid Fibers Reinforced Composites}

Thermoplastic composites reinforced with natural fiber, in general, show poor strength performance when compared to thermoset composites. Therefore, to acquire benefits of design flexibility and recycling possibilities, these natural fiber composites are hybridized with small amounts of synthetic fibers to make them more desirable for technical applications.

\subsection{Particle Reinforced Composites}

Compared to FRC, particle-reinforced composite (PRC) is not that effective by means of material strength and fracture resistance property. However, ceramic, metal, or inorganic particles restrict the deformation and provide good material stiffness. In recent days, PRCs are also getting a bit of attention due to their isotropic properties and cost-effectiveness. Moreover, these composites are manufactured using similar techniques used for monolithic material. PRCs are employed for civil applications such as roadways and concrete structures, where a high degree of wear resistance is expected. In concrete, cement acts as a binder material while aggregate of coarse rock or gravel as a filler material provides hardness and stiffness.

\subsection{Sheet Molded Composites}

Sheet-molded composites (SMCs) are fabricated by bonding homogeneous layers of materials using a compression molding process to form non-homogeneous composite laminates. The laminate is composed of layers and, in the case of FRP composites made of fiber sheets, buckling stability of the material improves with increasing the number of layers in the laminate. SMC shows the application in large structural components like automotive body parts consisting of high strength to weight ratio. Tensile properties of natural fibers can be defined by their chemical compositions. Tensile strength increases with an increase in cellulose content of the fibers, and decreases with increase in lignin content. Some of the mechanical and physical properties of frequently used fibers are displayed in Table 1. 
Table 1: Mechanical and physical properties of frequently used fiber materials

\begin{tabular}{|c|c|c|c|c|}
\hline Fiber & $\begin{array}{c}\text { Density } \\
\left(\mathbf{g m} / \mathbf{c m}^{\mathbf{3}}\right)\end{array}$ & Elongation $\mathbf{( \% )}$ & $\begin{array}{c}\text { Tensile } \\
\text { Strength }(\mathbf{M P a})\end{array}$ & $\begin{array}{c}\text { Young's } \\
\text { Modulus } \\
\mathbf{( G P a )}\end{array}$ \\
\hline Aramid & 1.4 & $3.3-3.7$ & $3000-3150$ & $63-67$ \\
\hline E-glass & 2.5 & $2.5-3$ & $2000-3500$ & 70 \\
\hline S-glass & 2.5 & 2.8 & 4570 & 86 \\
\hline Cotton & $1.5-1.6$ & $3-10$ & $287-597$ & $5.5-12.6$ \\
\hline Hemp & 1.48 & 1.6 & $550-900$ & 70 \\
\hline Jute & $1.3-1.46$ & $1.5-1.8$ & $393-800$ & $10-30$ \\
\hline Flax & $1.4-1.5$ & $1.2-3.2$ & $345-1500$ & $27.6-80$ \\
\hline Ramie & 1.5 & $2-3.8$ & $220-938$ & $44-128$ \\
\hline Sisal & $1.33-1.5$ & $2-14$ & $400-700$ & $9-38$ \\
\hline Coir & 1.2 & $15-30$ & $175-220$ & $4-6$ \\
\hline Kenaf & $0.6-1.5$ & $1.6-4.3$ & $223-1191$ & $11-60$ \\
\hline Bamboo & $1.2-1.5$ & $1.9-3.2$ & $500-575$ & $27-40$ \\
\hline Oil palm & $0.7-1.6$ & $4-8$ & $50-400$ & $0.6-9$ \\
\hline Betel nut & $0.2-0.4$ & $22-24$ & $120-166$ & $1.3-2.6$ \\
\hline $\begin{array}{c}\text { Sugarcane } \\
\text { bagasse }\end{array}$ & $1.1-1.6$ & $6.3-7.9$ & $170-350$ & $5.1-6.2$ \\
\hline
\end{tabular}

\section{LITERATURE REVIEW}

\subsection{Fiber Reinforced AMCs}

Sayman et al. studied the elasto plastic stress analysis of aluminium and stainless-steel fiber and found that under $30 \mathrm{MPa}$ pressure and at a temperature of $600^{\circ} \mathrm{C}$, good bonding between matrix and fiber was observed, moreover increase in the load carrying capacity of the laminated plate was also visualized. Onur Sayman analyzed the elastic-plastic thermal stress on steel fiber reinforced Aluminium metal-matrix composite beams and found that the intensity of the residual stress and the equivalent plastic strain are greatest at 0 orientation angle and concluded that the higher the orientation angle the lower the temperature that causes plastic yielding.

Cesim Atas and Onur Sayman reported that for steel fiber reinforced Al MMC plates, yielding begin at the edge of the laminated plates. They found that the yielding does not occur at the corner of the plate. Ding et al. investigated the behaviour of the unreinforced 6061 aluminium alloy and short fiber reinforced 6061 Al alloy MMC. They found that the addition of high-strength $\mathrm{Al} 2 \mathrm{O} 3$ fibers in the 6061 aluminium alloy matrix will not only strengthen the microstructure of the 6061 aluminium alloy, but also channel deformation at the tip of a crack into the matrix regions between the fibers and therefore con- strain the plastic deformation in the matrix which leads in reduction of fatigue ductility.

Woei-Shyan Lee et al. studied the effects of strain rate on the properties and fracture behaviour of laminated Carbon fiber reinforced 7075-T6Aluminium alloy and found that the flow stress increases with strain rate, but decreases with temperature. Work hardening rate decreases with increase in strain and temperature. A greater density of $\mathrm{Al}$ debris and fiber fracture was found at high strain rate for all temperature. Gudena and Hall studied the high strain rate compressive deformation behaviour of a continuous $\mathrm{Al} 2 \mathrm{O} 3$ fiber reinforced $\mathrm{Al}$ MMC tested in the longitudinal and transverse direction and found that in trans- verse direction, the composite exhibit strain rate similar to that of monolithic alloy.

Rams et al. studied the electroless nickel coated fiber reinforced Aluminium matrix composites and found that the wettability of the composite increases. This wettability 
enhancement and reduced damage on the fiber is due to Ni-Al-P transient intermetallic layer that is formed due to heating. Shi et al. studied the morphology and interfacial characteristics of aluminium matrix composites reinforced with the diamond fiber. The composite exhibit high thermal conductivity and low thermal expansion coefficient. Pressure-less metal infiltration process results in good bonding between the diamond fibers and the aluminiummatrix.

\subsection{Carbon Nanotube Reinforced Materials}

Qianqian Li et al. (2009) have proposed in their journal of improved processing of carbon nanotubes/magnesium alloy composites. In this study, a two-step process was applied. In first stage, a block copolymer was used as a dispersion agent to pre-disperse multiwall carbon nanotubes (MWNTs) on Mg alloy chip. Then the chip with the well dispersed MWNTs on their surface were melted and at the same time vigorously stirred. The molten MWNT Mg alloy composites were poured into a cylindrical mould to solidify quickly. For the predispersion step, the microstructures of the Mg alloy chip were studied under SEM. MWNTs were quite successfully dispersed on the surface of the $\mathrm{Mg}$ alloy chips. The mechanical properties of the MWNT/Mg composites were measured by compression testing. The compression at failure, the compressive yield strength and ultimate compressive strength have all been improved significantly up to $36 \%$ by only adding $0.1 \mathrm{wt} \%$ MWNTs to the Mg alloy.

C.S.Goh Wei et al. (2008) have proposed the development of novel carbon nanotubes reinforced magnesium nanocomposites using powder metallurgy technique. Carbon nanotubes (CNTs) reinforced magnesium nanocomposites were synthesized using the powder metallurgy technique followed by hot extrusion. Up to 0.3 wt.\% of CNTs were added as reinforcements. The effects of carbon nanotubes on the physical and mechanical properties of $\mathrm{Mg}$ were investigated. The thermo mechanical property results show an increase in thermal stability with increasing amount of CNTs in $\mathrm{Mg}$ nanocomposite. Mechanical property characterizations reveal an improvement of yield strength, ductility and work of fracture with higher weight percentages of CNTs incorporated. An attempt is made to correlate the physical and mechanical properties with the increasing weight fractions of carbon nanotubes in pure Mg matrix.

\section{PROCESSING TECHNIQUES FOR FIBER REINFORCED COMPOSITES}

Processing of FRP composite involves manufacturing of fiber preforms and then reinforcing these fibers with the matrix material by various techniques. Fiber preforms involve weaving, knitting, braiding, and stitching of fibers in long sheets or mat structure. Preforms are used to achieve a high level of automation with the assistance of robotics, which offers control over the fiber angleand the fiber content on every zone of the part to be molded.

Prepregs are a combination of fibers and uncured resin, which are pre-impregnated with thermoplastic or a thermoset resin material that only needs the temperature to be activated. These prepregs are ready-to-use materials where the readily impregnated layers are cut and laid down into the open mold. Dow Automotive Systems has developed VORAFUSE, a technique that combines epoxy resin with carbon fiber for prepreg applications to improve material handling and cycle time in the compression molding of composite structures. Working in collaboration with a variety of automotive companies, they have achieved significant weight reduction, which results in efficient manufacturing of CFRP composite structures.

\subsection{Hand lay-up process}

Figure 3 shows the hand lay-up, which is the most common and widely used open mold composite manufacturing process. Initially, fiber preforms are placed in a mold where a thin 
layer of anti adhesive coat is applied for easy extraction. The resin material is poured or applied using a brush on a reinforcement material. The roller is used to force the resin into the fabrics to ensure an enhanced interaction between the successive layers of the reinforcement and the matrix materials.

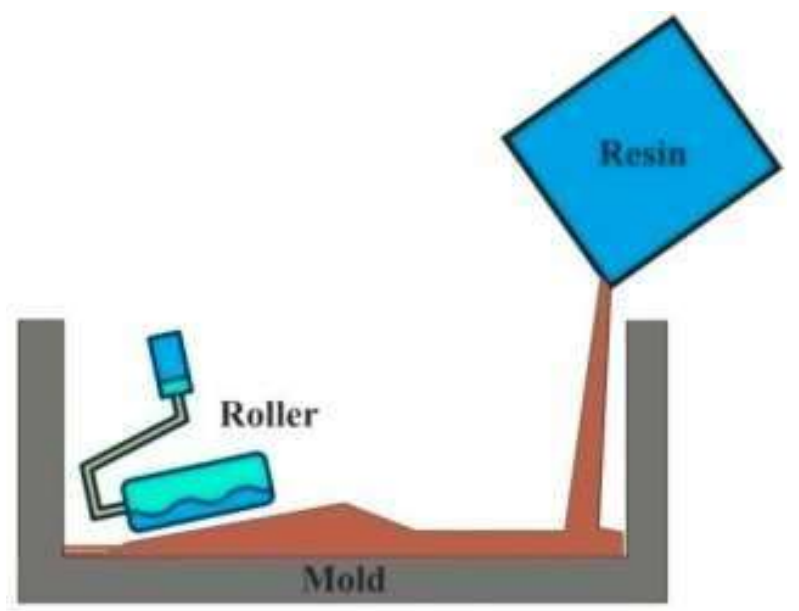

Figure 3: Hand lay-up process

\subsection{Spray-up process}

Spray-up technique is no different than hand lay-up. However, it uses a handgun that sprays resin and chopped fibers on a mold. Simultaneously, a roller is used to fuse these fibers into the matrix material. The process is illustrated in Figure 4. It is an open mold type of technique, where chopped fibers provide good conformability and quite faster than hand layup.

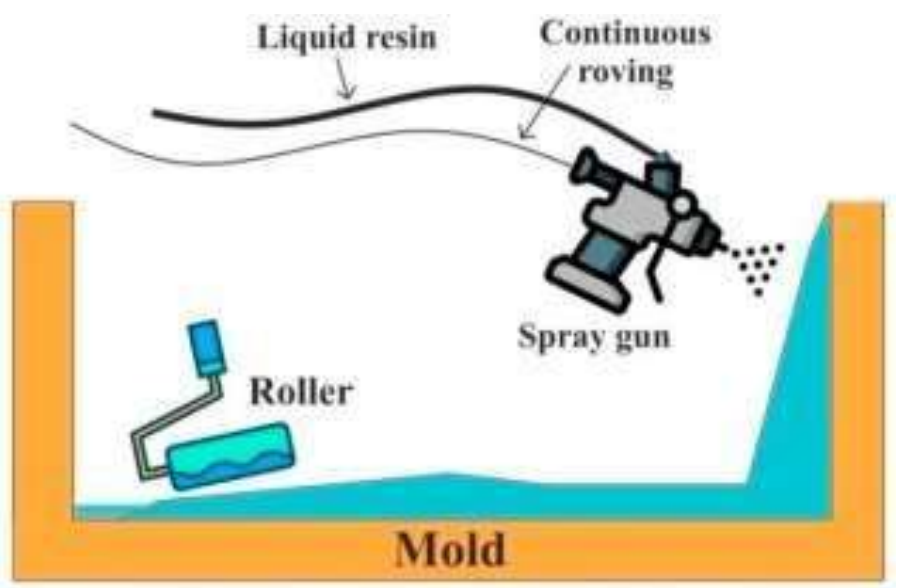

Figure 4: Spray-up process

\subsection{Resin transfer molding process}

The preform fiber reinforcement mat or woven roving arranged at the bottom half of the mold and preheated resin is pumped under pressure through an injector. The mechanism of the resin transfer molding (RTM) process can be understood with Figure 5. A variety of combinations of fiber material with its orientation, including 3D reinforcements, can be achieved by RTM. It produces high-quality, high-strength composite structural parts with surface quality matching to the surface of the mold. 


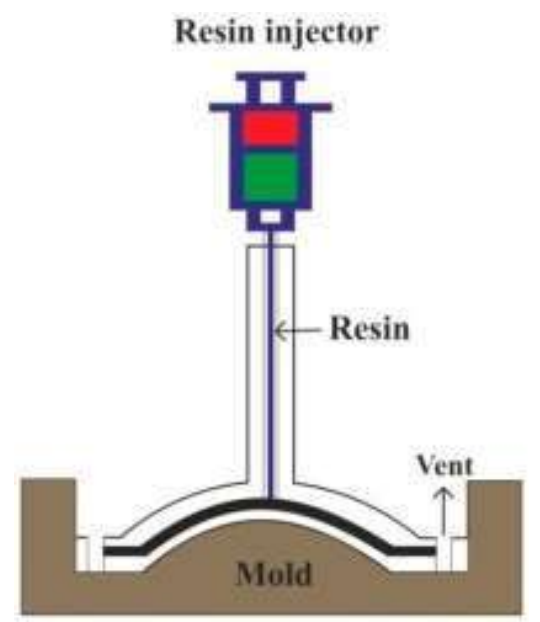

Figure 5: Resin transfer molding process

\subsection{Electrospinning process}

The emerging nanotechnology has provoked researchers to seek out new nanoscale fiber manufacturing techniques for composite manufacturing. An electrostatic fiber fabrication technique called electrospinning uses electrical forces to generate continuous fibers of two nanometers to several micrometers. Polymer solution ejected through spinneret forms a continuous fiber, which is collected at the collector shown in Figure 6. It serves enhanced physical and mechanical properties, flexibility over process parameters, high surface area to volume ratio, and high porosity; therefore it finds potential in diverse fields of biomedical applications such as wound healing, tissue engineering scaffolds, drug delivery, as a membrane in biosensors, immobilization of enzymes, cosmetics, etc.

Additive manufacturing (AM) offers a high level of geometrical complexity for the fabrication of fully customized objects as it takes advantage of computer-aided designing and also eliminates the requirement of molds, which saves cost and time of manufacturing process. AM is one of the leading technologies in composite manufacturing as it provides wide range over the selection of fiber volume and fiber orientation. It has the ability to transverse design idea into the final product quickly without the wasting material and cycle time, which makes it ideal for prototyping and individualization.

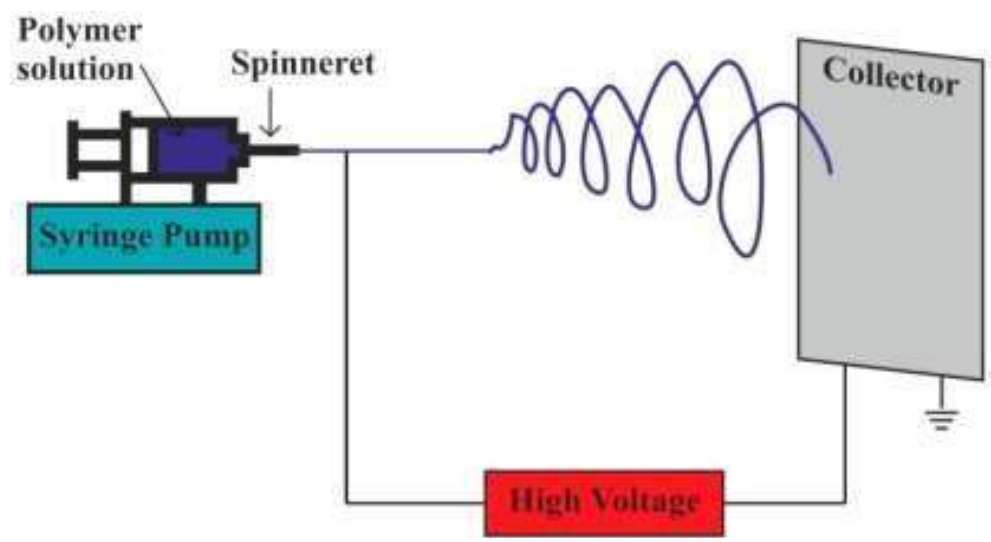

Figure 6: Electrospinning process 


\section{APPLICATIONS OF FIBER REINFORCED COMPOSITES}

There many applications of fiber reinforced composites in mechanical, automobile, aerospace and marine engineering fields.

\subsection{Mechanical applications of Fiber Reinforced Composites}

For the application of gear pair, polyoxymethylene (POM) with $28 \%$ glass fiber reinforcement revealed significant enhancement of about $50 \%$ in the load-carrying capacity, with lower specific wear rate when compared to unreinforced POM. Gear pair made of carbon-epoxy prepreg laminate was comparable to steel for the evaluation of static transmission error (STE) and mesh stiffness curves. Results showed a significant reduction in STE peak-to- peak value, which further resulted in improved noise, vibration, and harshness $(\mathrm{NVH})$ performance of the material.

In the automobile industry, there is remarkable growth in the demand for lightweight material to increase fuel efficiency with a reduction of emission. FRP composites are serving these demands, for example, for safe and efficient storage and transportation of gaseous fuels such as hydrogen, and natural gas pressure vessels are used. Pressure vessels made of FRP composite materials, when compared to metallic vessels; provide high strength and rigidity, improved corrosion resistance, and improved fatigue strength, besides being light in weight. A pressure vessel made of thermosetting resin and fiberglass reinforcement is displayed in Figure 7.

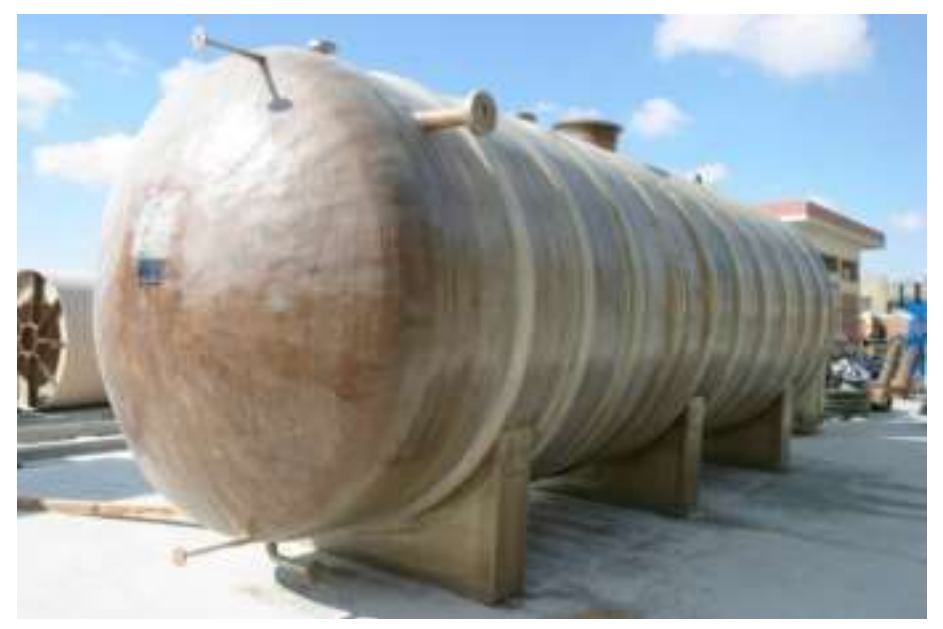

Figure 7: Pressure vessel made of thermosetting resin and fiberglass reinforcement

For the transportation of soil material, a dump truck uses a hydraulic system consisting of an actuator made of a telescopic hydraulic cylinder. There is a $96 \%$ weight reduction when the steel cylinder is replaced with a carbon fiber-reinforced epoxy resin composite. When this telescopic cylinder made of composite was installed, there was a 50\% reduction in the whole hydraulic system.

During a typical machining operation, interference between machine tool and workpiece produces high vibration in the cutting tool relative to the workpiece. Nearly half of the deflection in cutting tools comes from the headstock; therefore, headstock demands a high degree of damping property. A hybrid steel-composite headstock adhesively manufactured by glass fiber epoxy composite laminates served a $12 \%$ increase in stiffness and $212 \%$ increase in damping property for the application of a precision grinding machine.

A two-link flexible manipulator was developed using ionic polymer metal composite (IPMC), which manifests the potential of polymer-based composite materials for flexible 
joints and links in robotic assembly, as demonstrated in Figure 8. Sulfonated polyvinyl alcohol (SPVA), 1-ethyl-3-methylimidazolium tetra chloroaluminate (IL), and platinum (Pt) (SPVA/IL/Pt)-based IPMC manipulator links provide flexibility and compliant behavior during manipulating and handling of complex objects of different shapes and sizes.

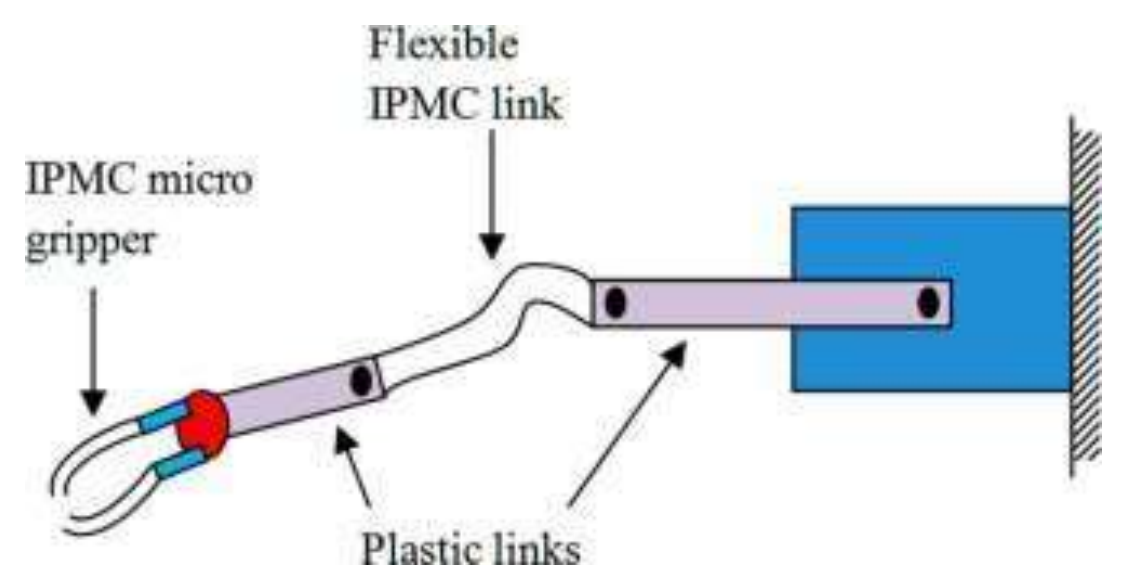

Figure 8: Flexible link manipulator

\subsection{Automotive applications of Fiber Reinforced Composites}

In an automobile braking system, the temperature can reach up to thousands of degrees centigrade. A monolithic metal fails to perform well as they are not able to withstand these higher temperatures. Therefore, carbon fiber-reinforced silicon carbide (C- Si) finds applications in brake materials for heavy vehicles, high-speed trains, and emergency brakes in cranes. Figure 9 shows a carbon-ceramic brake of a Chevrolet Corvette.

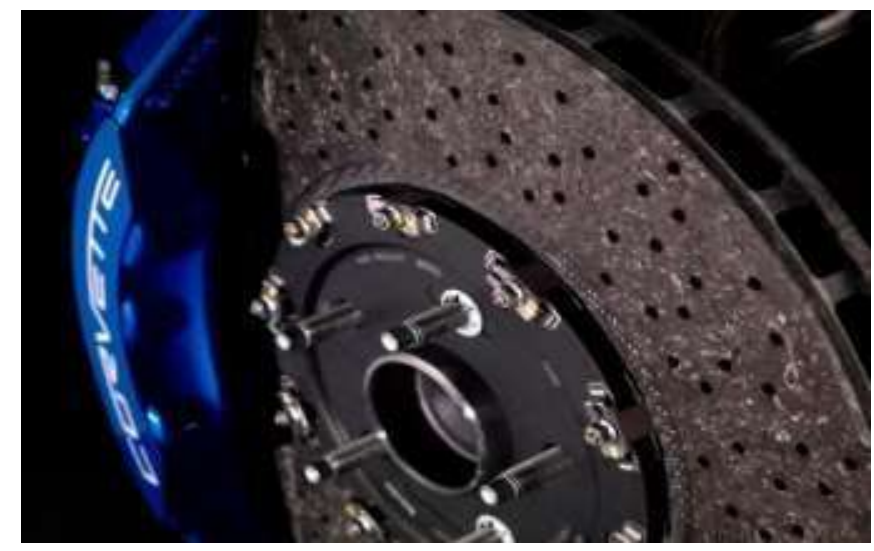

Figure 9: The braking system of corvette made of carbon-ceramic

Automobile body parts, such as engine hood, dashboards, and storage tanks, are manufactured by using reinforcements of natural fibers such as flax, hemp, jute, sisal, and ramie. For these composite structures VARTM manufacturing method was employed and liability is tested with structural testing and by using impact stress analysis. The result showed a reduction in the weight of the material with the enhancement in stability and strength. The improvement in safety features were measured under head impact criteria (HIC), and it was found that composite structures comprised of natural fiber reinforcements are reasonable for automobile body parts. Figure 10 displays exterior body parts of a model Volkswagen XL1 made of carbon fiber. 


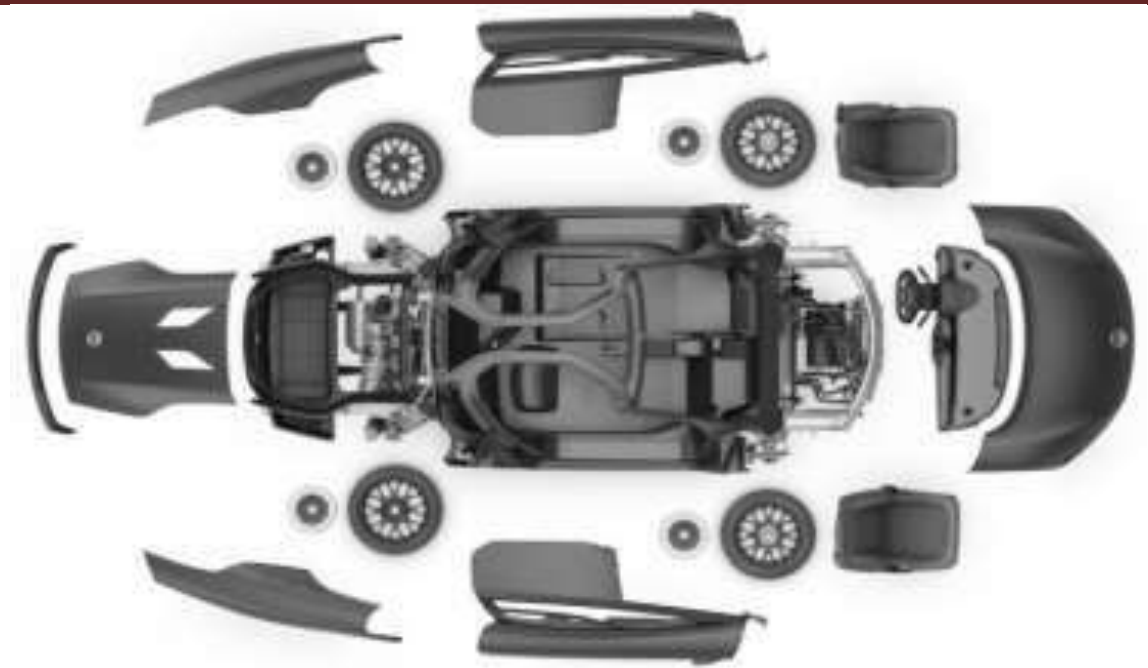

Figure 10: Volkswagen XL1 carbon fiber body parts

The composite structure comprises of biodegradable natural fibers which have found significant applications as sound and vibration absorption material in interior automobile components. Composite laminate with bamboo, cotton, and flax fibers with PLA fibers showed bending stiffness of $2.5 \mathrm{GPa}$, which is higher than all other composites.

\subsection{Aerospace applications of Fiber Reinforced Composites}

Application of FRP composite materials in the field of aerospace industries can be seen with the implementation of highly durable, thermal-resistant, lightweight materials for the aircraft structure due to their outstanding mechanical, tribological, and electrical properties. Natural fiber-reinforced thermoset and thermoplastic skins manifest the properties required for aircraft interior panels, such as resistance to heat and flame, serving easy recycling, and disposal of materials being cheaper and lightweight over conventional sandwich panels. Though FRP composite shows a variety of applications in the aerospace industry due to their superior mechanical properties and lightweight structure, they face difficulty in recycling. To overcome this, natural fiber/bio composite materials brought new prospects in the aerospace industry due to their biodegradability and lower cost.

Conductive fibers in the layer of fiber composite structure eliminate the requirement of separate wires for transceivers of communication devices. When voltage is applied to either layer of composite, it carries electric power to certain electric devices through the fibers. Aircraft wing boxes made of ramie fiber composites revealed a $12-14 \%$ decrease in weight. Hybrid kenaf/glass fiber-reinforced polymer composites showed enhanced mechanical properties with rain erosion resistance, suitable for aircraft application. Carbon fiberreinforced silicon carbide is applied for aircraft brakes to withstand high temperatures up to $1200^{\circ} \mathrm{C}$.

\subsection{Marine applications of Fiber Reinforced Composites}

CFRP shows enhanced mechanical properties, such as high strength to weight ratio, resistance to corrosion, fatigue, and temperature changes with low cost of maintenance. These properties make CFRP a perfect fit for propeller material in marine applications. Glass or carbon fiber skins with polymeric core sandwich composite panels have been used for the development of entire hulls and marine craft structures. 


\section{CONCLUSIONS}

1. There are numerous types of fibers available for fabrication of fiber-reinforced composites; those are categorized as natural and synthetic fibers. Synthetic fiber provides more stiffness, while natural fibers are cheap and biodegradable, making them environmentally friendly. Though both types of fibers have their efficacy in significant applications, latest research has revealed the exceptional performance of hybrid fiberreinforced composite materials.

2. Composite materials are fabricated with a number of different techniques, among which every technique is applicable for certain material. Effectiveness of manufacturing technique is dependent on the combination of type and volume of matrix or fiber material used, as each material possesses different physical properties, such as melting point, stiffness, tensile strength, etc. Therefore, manufacturing techniques are selected as per the choice of material.

3. Composite structures have shown improvement in strength and stiffness of material, with excellent reduction in weight. Composites have also revealed some remarkable features such as resistance to impact, wear, corrosion and chemicals, but these properties are dependent upon the composition of the material, type of fiber and type of manufacturing technique employed to fabricate them. In accordance with the properties required, composite materials find their applications in many desired fields.

\section{REFERENCES}

[1] Yashas Gowda, T.G.; Sanjay, M.R.; Subrahmanya Bhat, K.; Madhu, P.; Senthamaraikannan, P.; Yogesha, B. SSPolymer matrix-natural fiber composites: An overview. Cogent. Eng. 2018, 5, 1446667.

[2] Sherif, G.; Chukov, D.; Tcherdyntsev, V.; Torokhov, V. Effect of formation route on the mechanical properties of the polyethersulfone composites reinforced with glass fibers. Polymers 2019, 11, 1364.

[3] Chukov, D.; Nematulloev, S.; Zadorozhnyy, M.; Tcherdyntsev, V.; Stepashkin, A.; Zherebtsov, D. Structure, mechanical and thermal properties of polyphenylene sulfide and polysulfone impregnated carbon fiber composites. Polymers, 2019, 11, 684.

[4] Monteiro, S.N.; de Assis, F.S.; Ferreira, C.L.; Simonassi, N.T.; Weber, R.P.; Oliveira, M.S.; Colorado, H.A.; Pereira, A.C. Fique fabric: A promising reinforcement for polymer composites. Polymers 2018, 10, 246.

[5] Linul, E.; Vălean, C.; Linul, P.A. Compressive behavior of aluminum microfibers reinforced semi-rigid polyurethane foams. Polymers 2018, 10, 1298.

[6] Ferreira, F.; Pinheiro, I.; de Souza, S.; Mei, L.; Lona, L. Polymer composites reinforced with natural fibers and nanocellulose in the automotive industry: A short review. J. Compos. Sci. 2019, 3, 51.

[7] Pickering, K.L.; Efendy, M.G.A.; Le, T.M. A review of recent developments in natural fiber composites and their mechanical performance. Compos. Part. A-Appl. S. 2016, 83, 98-112.

[8] Lotfi, A.; Li, H.; Dao, D.V.; Prusty, G. Natural fiber-reinforced composites: A review on material, manufacturing, and machinability. J. Compos., 2019.

[9] Mehdikhani, M.; Gorbatikh, L.; Verpoest, I.; Lomov, S.V. Voids in fiber-reinforced polymer composites: A review on their formation, characteristics, and effects on mechanical performance. J. Compos. Mater., 2018, 53, 1579-1669.

[10] Dickson, A.N.; Ross, K.A.; Dowling, D.P. Additive manufacturing of woven carbon fiber polymer composites. Compos. Struct., 2018, 206, 637-643.

[11] Dixit, S.; Goel, R.; Dubey, A.; Ahivhare, P.R.; Bhalavi, T. Natural fiber reinforced polymer composite materials- A review. Polym. Renew. Resour., 2017, 8, 71-78. 